\author{
EVS29 Symposium \\ Montréal, Québec, Canada, June 19-22, 2016
}

\title{
Defining a Representative Vibration Durability Test for Electric Vehicle (EV) Rechargeable Energy Storage Systems (RESS)
}

\author{
J.M. Hooper ${ }^{1}, \mathrm{~J} \mathrm{Marco}^{2}$ \\ ${ }^{I}$ WMG, University of Warwick, Coventry,Warwickshire,CV4 7AL,UK,j.m.hooper@warwick.ac.uk \\ ${ }^{2}$ WMG, University of Warwick, Coventry, Warwickshire, CV4 7AL, UK, james.marco@warwick.ac.uk
}

\begin{abstract}
Summary
This study defines a process to devise random power spectral density (PSD) profiles that are representative of 100,000 miles of UK customer electric vehicle (EV) usage utilising vibration measurements from three contemporary EV's, for undertaking vibration durability evaluations of underfloor mounted rechargeable energy storage systems (RESS). This paper also presents a critical assessment of current random vibration test procedures available to engineers for validating the mechanical performance of EV RESS via comparing the shock response spectrum (SRS) and fatigue damage spectrum (FDS) of these standards to the SRS and FDS of 100,000 miles UK durability.
\end{abstract}

Keywords: RCS (Regulations Codes and standards), reliability, data acquisition, EV (electric vehicle), battery.

\section{Introduction}

In the past decade, decarbonising the tailpipe emissions of passenger vehicles has become an area of significant focus for automotive manufacturers, due to increasing environmental awareness with society and emerging government legislation mandating the development of carbon dioxide $\left(\mathrm{CO}_{2}\right)$ reducing technologies [1]. Vehicle electrification is a technology pathway being adopted by original equipment manufacturers (OEMs) to either reduce or eliminate tailpipe emissions. However, electric vehicles (EV's) that employ a rechargeable energy storage system (RESS) still face some significant barriers within the marketplace when compared to incumbent internal combustion engine (ICE) vehicle technology [2]. One of these barriers is ensuring that the RESS lasts the life of the product or maintains customer satisfactory performance over a warranted life (such as 10 years or 100,000 miles of customer usage).

To determine the in-service reliability of components, OEMs perform a variety of "life representative" durability tests during the design and prototype stages of the development process. Firstly, these tests ensure that new vehicle sub-assemblies and components are fit-for-purpose and meet the manufacturer's own duty of care requirements [3]. Secondly, it allows OEMs to obtain characterization data for simulations and Computer Aided Engineering (CAE) activities. Thirdly, it ensures that the product meets the legislative requirements for vehicle homologation [3].

Vibration durability tests play an important role in the selection of components. As discussed within [4-8], poorly integrated components, assemblies or structures subject to vibration can result in a significantly reduced service life or the occurrence of catastrophic structural failure through fatigue cracking or the work hardening of materials $[6,9,10]$. Within the context of EV's limited data exists that investigates the 
vibration durability of RESS components and assemblies to a predetermined life or in-service mileage [3]. Published research which defines the levels of vibration that RESS are exposed to during a predefined service life [2, 3], studies such as [11] have devised vibration test profiles from conventional internal combustion vehicles (ICV) rather than from an EV derivative. As a result, only generic vibration measurements were possible since it was not possible to mount the instrumentation at key locations on an EV (such as directly onto the HV RESS [2]). While [11] presents the PSD plot for the resultant vibration test profile for validating EV components, there is no discussion as to the derivation of the test profile. In particular, the relative exposure of the EV to different road surfaces and how such measurements were sequenced to form a representative vehicle life from which an accelerated life durability assessment of the design could be made.

The study presented in [2] defines the vibration experienced by the RESS within three commercially available EVs (Nissan Leaf, the Smart ED and the Mitsubishi iMiEV) when subjected to multiple durability surfaces at Millbrook Proving Ground UK. For each, the measured road surfaces are sequenced to emulate the vibration energy that the battery pack may be exposed too during a representative 10 year service life [2] resulting in a PSD for each vehicle. The generated PSD were compared to two current "random vibration tests" (discussed in section 2) of J2380 and BS62660. This study identified that both standards were too aggressive when compared to the measured data. However, the limitations of this initial study are that the vibration for each surface was sequenced using weightings from ICV structural durability procedure and not EV weightings, which may differ due to factors such as range anxiety. Also, the comparison between the standards did not consider that the vibration loading within SAE J2380 for the device under test (DUT) is achieved through multiple profiles for a single axis at altering Grms levels (discussed in section 2). Therefore a true determination of the severity of the profiles was not achieved by a simple comparison of PSD's for this profile. The paper also did not take the opportunity of defining a streamlined vibration profile based on the peak energy for each frequency for all the vehicles assessed that could be utilised for durability assessments that was representative of a given life.

Research presented within [12] defines a methodology for comparing different vibration standard types against vibration measurements from a Volvo C30 Electric via assessing the shock response spectrum (SRS) and fatigue damage spectrum (FDS) (discussed in section 4) of the recorded vibration data against the SRS and FDS of current RESS vibration standards. This method of comparison can overcome the inaccuracies identified within [2]. However, the limitation of this study is that the vehicle was only driven over a rumble strip test track and not a variety of representative surfaces. A test profile from a single surface will only excite particular vibration energy for a particular set of frequencies which is unrepresentative of real world use. It was also assumed by the study that 800 hours of driving on this single surface type was representative of 15 years customer operation.

In summary, no one study has taken measured EV vibration data from multiple surface types, synthesised a test profile using surface sequencing representative of an EV durability life and assessed the suitability of this profile to known vibration standards within a vehicle durability context.

This paper is a continuation of the study discussed in [2] and utilises the same baseline vibration measurements. It defines the process taken to develop a vibration profile that could be applied by researchers in academia and industry to determine the vibration durability behaviour of a RESS from recorded vibration data from multiple EV's over different customer representative surfaces. It assesses the severity of the measured vibration to all current vibration standards devised for evaluating EV RESS and their associated sub-components via applying the methodology defined in [12] where the calculated FDS and SRS of the synthesised road load data is compared to defined EV vibration test standards.

This paper is structured as follows; section 2 presents a brief critical analysis of vibration profile types available to engineers within test standards within the context of component durability. In addition it identifies standards that are available to vehicle manufacturers for vibration validation of EV components that utilise a suitable vibration methodology. Section 3 discusses the vehicle measurement and raw data collection method. It defines the stages of deriving vibration test profiles that are representative of 100,000 miles of durability from this measured road load data. Section 3 concludes by presenting the derived vibration test profiles. Section 4 compares the synthesised test profiles using the SRS and FDS method to the vibration standards identified within section 2. Finally, discussion and conclusions are presented in Sections 5 and 6 respectively. 


\section{Vibration test standards}

The following section defines and evaluates the vibration profiles available to engineers within the context of vehicle durability. It defines suitable vibration tests that will be compared to the synthesized vehicle data within this study.

\subsection{Types of vibration profiles used within test standards}

Vibration can be measured in the "real world" and then replicated using shaker systems in a laboratory [6]. Whilst vibration measurements can be reproduced in the time domain on shaker system, test standards typically specify tests that are applied to the DUT in the frequency domain for purposes of standardisation and repeatability. Tests performed in the frequency domain can be compressed, thus allowing engineers the ability to replicate many years of customer usage in a matter of days. There are typically two categories of frequency domain vibration profiles suitable for the assessment of components fitted to wheeled road vehicles; they are sinusoidal vibration and random vibration.

\subsubsection{Sinusoidal vibration}

Typically sine waves are defined by a frequency or frequency range in $\mathrm{Hz}$ and acceleration. The acceleration is defined with respect to the gravitational constant $\mathrm{g}\left(9.81 \mathrm{~ms}^{-1}\right)$. With sinusoidal tests, both the frequency and acceleration can vary with time. A common sine vibration test is to sweep from a low to a high frequency with fixed or varying acceleration [13]. The speed that a sine wave can change in frequency is defined by a "sweep rate". This can be either a linear sweep rate that is expressed in $\mathrm{Hz} /$ second or a logarithmic sweep defined in octaves / minute [6]. An octave / minute sweep has the advantage of applying the same number of sinusoidal cycles per frequency. Sinusoidal vibration profiles do not represent accurately the in-service vibration witnessed by chassis mounted automotive components $[6,13]$. However they are often used for simple robustness evaluations at fixed frequencies or via resonance dwell (where the test purposely tracks and excites the natural frequency of the test item to determine its resistance to fatigue when forced into a resonance condition).

\subsubsection{Random vibration}

For a more realistic simulation of a real life automotive environment, engineers can choose to apply a broad band random vibration to a test item which is controlled to predetermined criteria to ensure test repeatability. Random vibration is defined as "noise whose instantaneous amplitude is not specified at any instant of time" [14]. A true random signal will have a frequency content that varies in acceleration and never repeats with time. It could therefore be said that; unlike a swept sine test, which influences individual frequencies, a random vibration test will influence many frequencies simultaneously. Because random vibration excites a defined band of frequencies, resonant frequencies within the item under evaluation are excited regularly and together, subsequently causing interactions which typically would not occur within a sine vibration test [6]. Random vibration testing is also more representative of road surface induced vibration phenomena on wheeled vehicles and subsequently is more desirable for accelerated life testing of chassis mounted automotive components [6]. Random vibration profiles are generated via applying a fast Fourier transform (FFT) to the measured vibration signal to convert it from the time domain to the frequency domain.

To reproduce a random signal on a shaker table it is necessary to define parameters that are applicable and representative of the operational environment of the item and replicates the vibration energy within the frequencies representative of the service conditions. Random test profiles are defined as amplitude against frequency which will have an upper and lower frequency restriction (such as $5 \mathrm{~Hz}$ to $190 \mathrm{~Hz}$ ).

With random vibration profiles, because the acceleration is applied over a spectrum of many frequencies, the level is expressed as the quantity of $\mathrm{g} \mathrm{rms}^{2}$ in a $1 \mathrm{~Hz}$ bandwidth or grms $\mathrm{grz}^{2} \mathrm{~Hz}$ [14]. However, within test standards it is more commonly expressed as $\mathrm{g}^{2} / \mathrm{Hz}$. This unit of $\mathrm{g}^{2} / \mathrm{Hz}$ describes the average power seen in a $1 \mathrm{~Hz}$ bandwidth, i.e. the power spectral density (PSD). The area below the curve is the energy content of the test profile and is a combination of an average level over the test bandwidth and represents the $\mathrm{g}$ rms or more commonly referred to as the Grms. The Grms can be calculated using equation 1 where the bandwidth in $\mathrm{Hz}$ is defined by $B W$ and the $\mathrm{g}^{2} / \mathrm{Hz}$ value by $P S D$.

$$
\text { Total Grms }=\sqrt{B W \times P S D}
$$




\subsection{Vibration standards for the evaluation of EV battery assemblies}

Section 2.1 highlighted that within the context of vibration durability, random vibration profiles are the most representative method of conducting a test within the frequency domain. Therefore only random vibration standards designed for the testing of EV RESS and subcomponents are reviewed within this section. Table 1 summarises the three key random vibration test specifications currently available to EV manufacturers and researchers. Additional information on these standards is discussed in [2, 12].

Table 1: Vibration standards (Note all standards illustrated test the X, Y and Z axis of the DUT) [15-17]

\begin{tabular}{|c|c|c|c|c|c|}
\hline Standard & $\begin{array}{c}\text { Other standards } \\
\text { referencing this } \\
\text { specification }\end{array}$ & $\begin{array}{c}\text { Application } \\
\text { level }\end{array}$ & $\begin{array}{c}\text { Test } \\
\text { frequency } \\
\text { range }(\mathrm{Hz})\end{array}$ & Peak Grms for random PSD & Test duration per axis \\
\hline $\begin{array}{c}\text { SAE } \\
\text { J2380 }\end{array}$ & $\begin{array}{l}\text { SAND } 3123 \\
\text { UL } 2580 \\
\text { USABC } \\
\text { Procedure } 10 \\
\text { (note SAEJ2380 } \\
\text { based on this } \\
\text { standard) }\end{array}$ & $\begin{array}{l}\text { Module and } \\
\text { battery } \\
\text { (in use for } \\
\text { assessment of } \\
\text { cells) }\end{array}$ & $\begin{array}{l}10 \text { to } \\
190 \mathrm{~Hz}\end{array}$ & $\begin{array}{l}\text { Z Axis profile } 1: 1.9 \& 0.75 \mathrm{Grms} \\
\text { Z Axis profile } 2: 1.9 \& 0.75 \mathrm{Grms} \\
\text { Z Axis profile } 3: 1.9 \& 0.75 \mathrm{Grms} \\
\text { X \& Y Axis Profile: } 1.5 \& 0.4 \\
\text { Grms }\end{array}$ & $\begin{array}{l}\mathrm{Z} \text { Axis Profiles } 1,2 \text { and } 3 \text { conducted } \\
\text { at } 1.9 \text { grms for } 9 \text { mins each. } \\
Z \text { Axis Profiles } 1,2 \text { and } 3 \text { conducted } \\
\text { at } 0.75 \text { Grms for } 5 \text { hours and } 15 \text { mins } \\
\text { each } \\
X \text { and Y Axis Profile conducted at } 1.5 \\
\text { grms for } 10 \text { mins and } 48 \text { seconds each } \\
X \text { and Y Axis Profile conducted at } 0.4 \\
\text { Grms for } 38 \text { hours each }\end{array}$ \\
\hline $\begin{array}{c}\text { ISO } \\
12405: 2 \\
2012\end{array}$ & $\begin{array}{c}\text { None at time of } \\
\text { writing }\end{array}$ & $\begin{array}{c}\text { Module, } \\
\text { battery (Cells } \\
\text { tested to } \\
\text { BS62660) }\end{array}$ & 5 to $200 \mathrm{~Hz}$ & $\begin{array}{l}\text { X axis profile: } 0.96 \mathrm{Grms} \\
\text { Underfloor Y axis profile: } 0.96 \\
\text { Grms } \\
\text { Z axis profile: } 1.44 \mathrm{Grms}\end{array}$ & $\begin{array}{l}21 \text { hours per axis for } 1 \text { sample } \\
15 \text { hours per axis for } 2 \text { samples } \\
12 \text { hours per axis for } 3 \text { samples }\end{array}$ \\
\hline BS62660 & ISO $12405-2$ & Cells & $\begin{array}{c}10 \text { to } \\
2000 \mathrm{~Hz}\end{array}$ & $2.83 \mathrm{Grms}$ & 8 hours per axis \\
\hline
\end{tabular}

SAE J2380, ISO12405 and BS62660 are illustrated at their desired test Grms levels in Figure 1. It must be noted that the severity of these test is difficult to compare using their PSD levels alone, as their severity is a combination of their PSD levels and their duration.

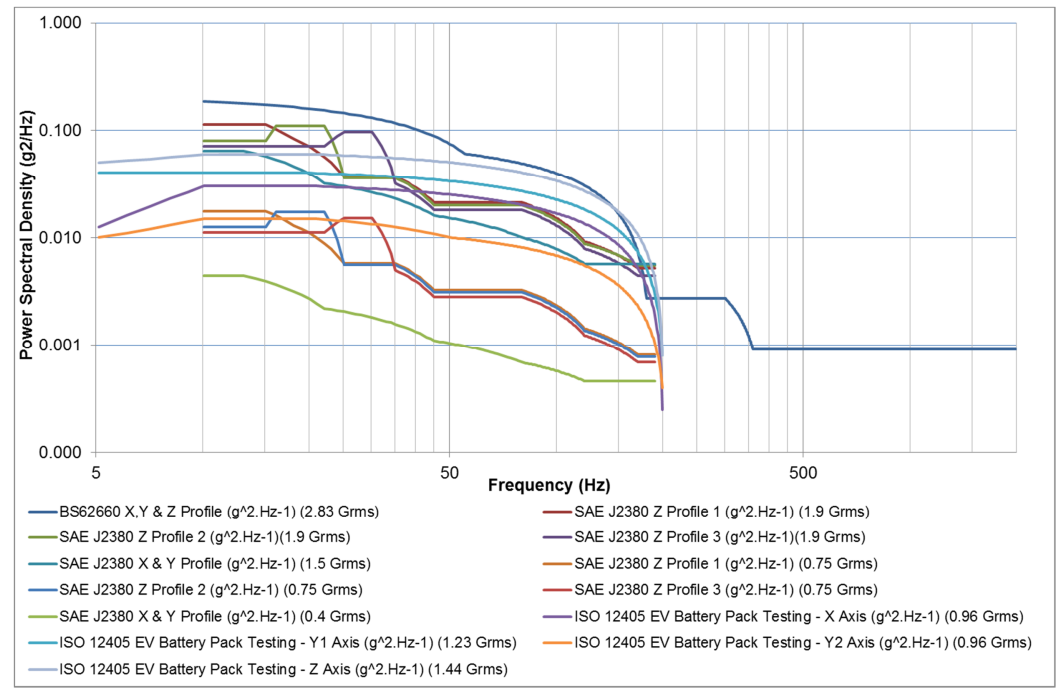

Figure 1: Test profiles defined in SAEJ2380, ISO12405 and BS62660 at specified Grms levels

\section{Development of a random vibration profile representative of 100,000 miles durability}

The following section summarises the experimental method employed to measure the vibration experienced by the RESS with contemporary EV products when subjected to road surfaces typically associated with normal customer usage. It defines the stages associated with converting these vehicle measurements into a 
random vibration profile that could be replicated on either a hydraulic or electromagnetic shaker system. A summary of this process is presented graphically in Figure 2.

The commercially available nCode 11.1 software was employed within this study to process the desired PSD plots for each of the X, Y and Z axes, and the associated FDS and SRS data. For completeness the theory behind the software is discussed.

\begin{tabular}{|c|c|c|c|c|}
\hline $\begin{array}{c}\text { Collect } \\
\text { representative } \\
\text { road surface } \\
\text { measurements in } \\
\text { time domain }\end{array}$ & $\begin{array}{c}\text { Sequencing of } \\
\text { data to 100,000 } \\
\text { miles } \\
\text { representative to } \\
\text { EV use }\end{array}$ & $\begin{array}{c}\text { Convert to } \\
\text { frequency domain } \\
\text { via FFT }\end{array}$ & $\begin{array}{c}\text { Apply test duration } \\
\text { and apply desired } \\
\text { test frequency range }\end{array}$ & $\begin{array}{c}\text { Derived test PSD } \\
\text { and Grms level }\end{array}$ \\
\hline
\end{tabular}

Figure 2: Process of generating a random PSD from road load data

\subsection{Collecting representative road surface data}

The vibration was measured from the RESS of three different commercially available EVs when driven over the specialised durability surfaces available at Millbrook Proving Ground. The three EV's evaluated were the Smart Electric Drive (ED), Nissan Leaf and Mitsubishi iMiEV. Additional information on the vehicle specifications are presented in $[2,18]$. Each EV was instrumented with two tri-axial accelerometers directly mounted on the battery system. The collection of the road load data was conducted using LMS V8 SCADAS mobile input cards installed into a single LMS SCM05 mainframe which logged the vibration response of each accelerometer via LMS "Test.Xpress" Time Data Acquisition. The accelerometers used were Piezoelectric Tri-axial ICP accelerometers (PCB 356B08), which were mounted to the desired location of the vehicle via a mounting base and Hottinger Baldwin Messtechnik GmbH (HBM) X60 adhesive. Data was collected at a sample rate of $2000 \mathrm{~Hz}$ which was 2.5 times the maximum desired post processed data frequency, which was $800 \mathrm{~Hz}$. The data was recorded using the SAE J670e vehicle axis convention shown in Figure 3.

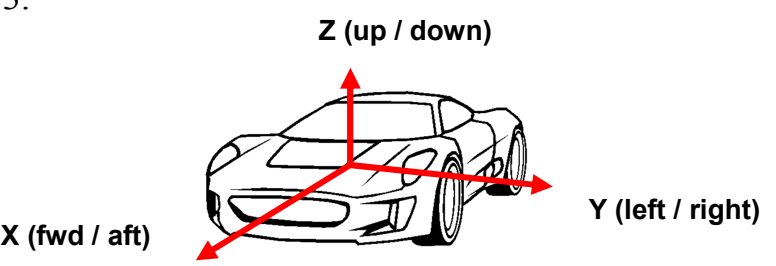

Figure 3: Vehicle axis convention in accordance with SAE J670e [3, 19]

Table 2: Description of measured proving ground surfaces [2]

\begin{tabular}{|c|c|c|}
\hline Road surface & $\begin{array}{l}\text { Road surface } \\
\text { classification }\end{array}$ & Road surface description \\
\hline Belgian pave & Urban & $\begin{array}{l}\text { Industry-standard surface for evaluating vehicle's noise vibration and harshness and } \\
\text { durability. } 1.45 \mathrm{~km} \text { of block granite paving. }\end{array}$ \\
\hline City course & Urban & $\begin{array}{l}\text { Level asphalt paved surface with multiple tight turns, speed hump and posted speed } \\
\text { limits typical of an urban driving environment. }\end{array}$ \\
\hline Pot holes & Urban & $\begin{array}{l}\text { Two large simulated pot holes, made of cast iron laid into the concrete surface of the } \\
\text { road. }\end{array}$ \\
\hline Random waves & Urban & $\begin{array}{l}\text { Undulating surface out of phase, inducing maximum suspension travel and high } \\
\text { amplitude low frequency input to vehicle structure. }\end{array}$ \\
\hline Sine waves & Urban & Sine waves out of phase, for high frequency input to the vehicle interior and structure. \\
\hline Twist humps & Urban & $\begin{array}{l}\text { Series of } 10 \text { handed angled humps of tarmac construction that has been developed to } \\
\text { apply torsional chassis inputs. }\end{array}$ \\
\hline Cats eyes $(30 \mathrm{mph})$ & Rural & 44 cats eyes along a $90 \mathrm{~m}$ length of track \\
\hline Cats eyes $(50 \mathrm{mph})$ & Rural & 44 cats eyes along a $90 \mathrm{~m}$ length of track \\
\hline Handling circuit & Rural & A concrete paved $6 \mathrm{~m}$ wide track with varying camber. Typical of rural roads. \\
\hline Hill route (loop 1) & Rural & $\begin{array}{l}\text { A simulated alpine road which has numerous assents, descents and bends with } \\
\text { changing camber. }\end{array}$ \\
\hline $\begin{array}{l}\text { High Speed Circuit } \\
\text { (HSC) }\end{array}$ & Motorway & $\begin{array}{l}\text { A circular constant radius banked concrete paved track constructed to simulate } \\
\text { motorway driving conditions. }\end{array}$ \\
\hline $\begin{array}{l}\text { Mile straight (part } \\
\text { throttle) }\end{array}$ & Motorway & Long, precisely levelled surface with fast approach and departure lanes. \\
\hline $\begin{array}{l}\text { Mile straight (wide } \\
\text { open throttle) }\end{array}$ & Motorway & Long, precisely levelled surface with fast approach and departure lanes. \\
\hline
\end{tabular}


The vibration response at each of the test locations was recorded by driving the vehicles over the durability surfaces at Millbrook Proving Ground. A description of the different road surfaces utilised for vehicle measurement is provided in Table 2. Measurements of multiple surface types and conditions commensurate with those witnessed during a vehicle's life time were recorded. These surfaces were selected in accordance with the Millbrook structural durability procedure [20] which defines surfaces and a driving framework typical of European customer operation. All vehicles were assessed with the same driver and passenger to ensure consistency in vehicle payload and repeatability of measurement methodology. Each car was charged to $100 \%$ state of charge (SOC) prior to the start of vehicle measurement and tyres were inflated to the manufacturers recommended "normal operation" pressure.

\subsection{Sequencing of surfaces to represent an EV service life}

To generate a representative vibration profile, a random PSD must be generated that is a combination of a variety of different surfaces and operational environments. These surfaces must be sequenced and repeated in a manner that is consummate with typical usage behaviour. Within this study a known whole vehicle durability schedule was employed as a framework to define the number of repeated road surfaces that would be sequenced together to form 100,000 miles of proving ground durability. This procedure was the Millbrook structural durability schedule [20]. While this procedure represents an internal organisational standard, it has evolved over 20 years of experience and is currently employed by a number of leading OEMs [2]. It defines a number of repeats for each measured surface to replicate a representative vehicle life within a European market. The original surface weighting for each surface classification is illustrated in Table 3.

Table 3: Surface classification weightings [20]

\begin{tabular}{|c|c|c|}
\hline $\begin{array}{c}\text { Surface } \\
\text { classification }\end{array}$ & $\begin{array}{c}\text { Original Millbrook structural durability surface } \\
\text { classification weighting (\%) }\end{array}$ & $\begin{array}{c}\text { Revised surface classification weighting - based on 2014 } \\
\text { University of Warwick study of BEV journeys (\%) }\end{array}$ \\
\hline Urban & 45 & 37.3 \\
\hline Rural & 31 & 39.1 \\
\hline Motorway & 24 & 23.5 \\
\hline
\end{tabular}

Within this study, a new surface weighting factor based on the road surface classification by drivers of battery electric vehicles (BEV) (shown in Table 3) undertaken by a separate study at the University of Warwick was applied to the surface repeats defined in [20]. The revised repeats of each test surface with this BEV weighting applied for a cumulative mileage of 100,000 miles is defined in Table 4.

Table 4: Number of repeats of each measured Surface to replicate 100,000 miles of EV customer usage

\begin{tabular}{|l|c|c|c|c|}
\hline $\begin{array}{l}\text { EV Study Surface } \\
\text { Relating to Module }\end{array}$ & $\begin{array}{c}\text { Surface in } \\
\mathbf{k m}\end{array}$ & $\begin{array}{c}\text { Classification of } \\
\text { Surface }\end{array}$ & $\begin{array}{c}\text { Repeats of Surface Required to Simulate } \\
\mathbf{1 0 0 , 0 0 0} \text { Miles (160,934km) of BEV weightings }\end{array}$ & $\begin{array}{c}\text { Total Distance } \\
\text { in km }\end{array}$ \\
\hline Belgian Pave & 1.45 & Urban & 3395 & 4923 \\
\hline Cats Eyes 30mph & 0.16 & Rural & 5295 & 847 \\
\hline Cats Eyes 50mph & 0.16 & Rural & 5295 & 847 \\
\hline City course & 1.29 & Urban & 37177 & 47958 \\
\hline Handling Circuit & 4.51 & Rural & 1933 & 8719 \\
\hline Hill route (Loop 1) & 1.77 & Rural & 29695 & 52560 \\
\hline HSC & 5.95 & Motorway & 2851 & 16961 \\
\hline Mile Straight (PT) & 1.29 & Motorway & 8141 & 10502 \\
\hline Mile Straight (WOT) & 1.29 & Motorway & 8141 & 10502 \\
\hline Pot Holes & 0.16 & Urban & 306 & 49 \\
\hline Random Waves & 0.64 & Urban & 6791 & 4346 \\
\hline Sine Wave & 0.16 & Urban & 6813 & 1090 \\
\hline Twist Humps & 0.16 & Urban & 10186 & 1630 \\
\hline TOTAL (km) & & & & $\mathbf{1 6 0 9 3 4}$ \\
\hline
\end{tabular}

Each measured surface from each of the three test vehicle were sequenced within "nCode 11.1 glyphworks" using the test schedule create function. 


\subsection{Converting data to frequency domain via FFT}

Once the time domain data has been sequenced to represent 100,000 miles of UK BEV usage, the measured excitation is transferred from the time domain to the frequency domain so that a PSD profile suitable for a shaker system application can be generated. This is achieved via the use of a Fourier transform (FT). More specifically, a version known as the discrete Fourier transform (DFT) as this can very readily be implemented by using an efficient set of algorithms on computers, known as the FFT [21], which is illustrated in Equation 2.

$$
x_{k}=\sum_{n=0}^{N-1} x_{n} e^{-\frac{2 \pi i}{N}} k n
$$

Where $x_{n}$ represents a complex time-domain data set, $x_{k}$ - a complex frequency-domain data set and $N$, the size of the data sets (which are assumed to be equal). The notation used in the DFT one sees two indices: $n$ and $k[21,22]$. It must be noted that within the application of Fourier methods to time domain data, is that the frequency representation of a periodic waveform may represent a much smaller amount of information than the time representation [21,22]. Fourier methods also have the advantage that they can distinguish frequency information within recorded data that is hidden within signal noise [21, 22].

\subsection{Determination of test frequency range}

A significant component of a vibration test profile is the chosen frequency range under assessment. The frequency range is typically defined by the capabilities of the shaker facilities and the frequency band where the peak energy occurs within the measured data. 5 to $200 \mathrm{~Hz}$ was chosen for the EV RESS test profiles within this study. A peak frequency of $200 \mathrm{~Hz}$ was chosen to ensure that it could be replicated on hydraulic shakers (which typically display performance run off above 250 to $300 \mathrm{~Hz}$ [23, 24]), whilst a 5 $\mathrm{Hz}$ starting point was chosen so that the profile could be conducted on electromagnetic shaker facilities which typically cannot replicate frequencies below $5 \mathrm{~Hz}$ (due to the lower displacement associated with these facilities). Reviewing PSD's of the test data highlighted that the majority of vibration energy occurred between 3 to $120 \mathrm{~Hz}$.

\subsection{Determination of synthesised test duration}

It is theoretically possible to compress a synthesised PSD to any duration while maintaining the same energy content in the signal, however a high time-forcing factor can cause other damage mechanisms during a test than during real service life [12]. As discussed in $[2,18]$ the shorter the duration of the test profile, the greater the severity of the shock loads applied to the system to achieve the desired fatigue damage spectrum. Because the application of a compression factor to achieve the desired test duration is linked to the SRS and FDS, these two concepts are discussed prior to outlining the test durations specified for the test profiles within this study.

\subsubsection{Fatigue damage spectrum (FDS)}

The simplest model of a dynamic system is the Single Degree of Freedom (SDOF) system is presented in Figure 4.

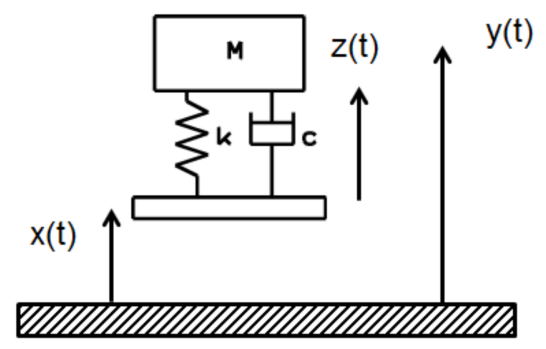

Figure 4: Single degree of freedom dynamic system model [12]

The system consists of a mass, a spring and a viscous damper. The system is excited by the motion $\mathrm{x}(\mathrm{t})$ the mass starts to oscillate [12]. The oscillation can be described either as the relative motion of the spring, $z(t)$ or as the absolute motion of the mass, $y(t)$ [12]. This model assumes fatigue to be caused by (or proportional to) the relative motion $z(t)$ in the structure. If a cycle count of the obtained motion $z(t)$ is performed, the damage due to the excitation $\mathrm{x}(\mathrm{t})$ can be estimated [12]. If such cycle counting is done for 
SDOF systems with different resonance frequencies and the resulting damage plotted as a function of the resonance frequency, the FDS is obtained [25]. The FDS is directly related to damage (if the damage mechanism is fatigue) and it can be calculated for all types of signals.

When calculating the FDS the relative damping of the SDOF system must be specified in order to get the amplitude of the response [12]. Within all the data presented within this paper, the damping ratio was assumed to be $5 \%$. Within the calculation of the FDS it is assumed that the fatigue damage varies exponentially with the stress [12]. This life-strength relationship is defined by the Basquin equation [25].

$$
C=S^{b} N_{f}
$$

Where $N_{f}$ is the life-length, and the stress, $\mathrm{S}$, is obtained from

$$
S=K z(t)
$$

In the calculations the value of the Basquin coefficient, $b$, is set to 4 . This is a material parameter and can vary between 3 and 10.4 was chosen as the value for the coefficient of $b$ based on the study discussed in [12]. The stiffness of the system, $K$, and the Basquin coefficient $C$ were also set to the same parameters of 1000 and 1, respectively as defined in [12] to assist correlation between studies. It must be highlighted that fatigue damage in real life is more complicated and therefore the FDS is utilised as a comparative measure within this study of fatigue potential of different test profiles and is not presented as an absolute measure of fatigue loading.

\subsubsection{Shock response spectrum (SRS)}

The SRS is calculated using a similar methodology as the FDS. Instead of performing cycle counting on the relative motion $\mathrm{z}(\mathrm{t})$, in Figure 1, the absolute maximum response of the mass $\mathrm{y}(\mathrm{t})$ is determined and plotted as a function of the resonance frequencies. The relative damping used in the SRS calculations was $5 \%$. For a test with a sinusoidal signal the maximum response was calculated by multiplying the excitation amplitude with the Q-factor. Where $\rho$ is the relative damping of the SDOF system.

$$
Q=\frac{1}{2 \rho}
$$

\subsubsection{Test duration of synthesized test profile}

It is possible to compress the test duration of random vibration durability tests by essentially increasing the Grms level of the synthesised PSD so that the same FDS is achieved in less time. To determine if a profile is too aggressive through excessive test time compression, nCode V11.1 allows the user to check the severity of the peak loading applied to the system by comparing the SRS of the synthesised PSD to that of the combined SRS of each measured surface to ensure that the shock loading is not outside that of the original measurements.

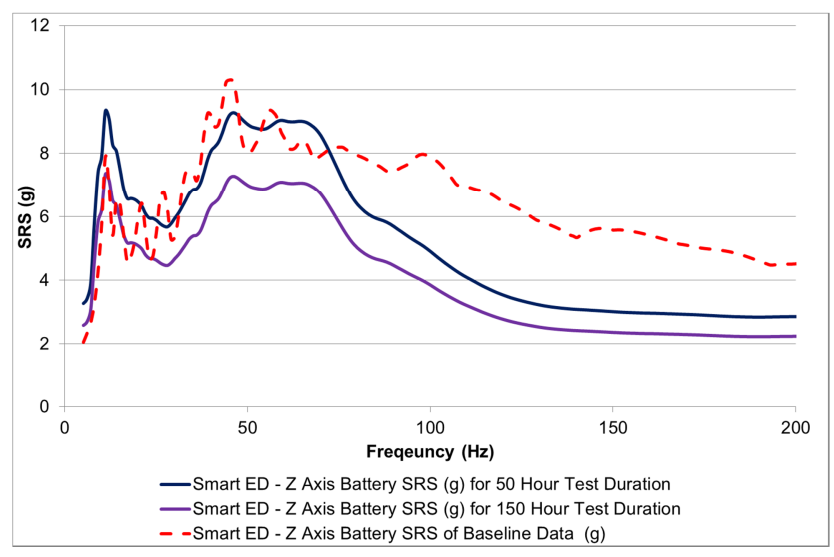

Figure 5: Effect of test duration of derived PSD's SRS in relationship to the SRS of un-sequenced surface data

Within this study two different test durations of 50 hours and 150 hour per axis were chosen. 50 hours was chosen so that 1 hour was representative to 2000 miles of durability loading in the desired test axis. 150 hours per axis was chosen as a conservative test duration that would result in lower shock loading and subsequently a higher degree of correlation with the in-service environment. Figure 5 shows a SRS of each of the two test durations compared to the SRS analysis of the pre sequenced data in $g$ (as shown by the red 
dashed line in Figure 5). From this data it can been seen that the 150 hour test duration is well within the SRS of the baseline SRS, whilst the 50 hour test has a greater shock loading than the pre sequenced data from 5 to $20 \mathrm{~Hz}$ and 55 to $70 \mathrm{~Hz}$ which indicates that this test maybe over accelerated with respect to its time compression within these frequencies.

\subsection{Synthesised vibration test profiles for 100,000 miles durability}

To define a generic test profile that would be suitable for a wide range of passenger EV's the generated PSD for each axis from each vehicle were overlaid. The peak values were selected. These peak values were then used to derive a simplified PSD that enveloped the greatest vibration witnessed by the RESS within A and C segment EV's within this study. This peak enveloping process is illustrated in Figure 6.

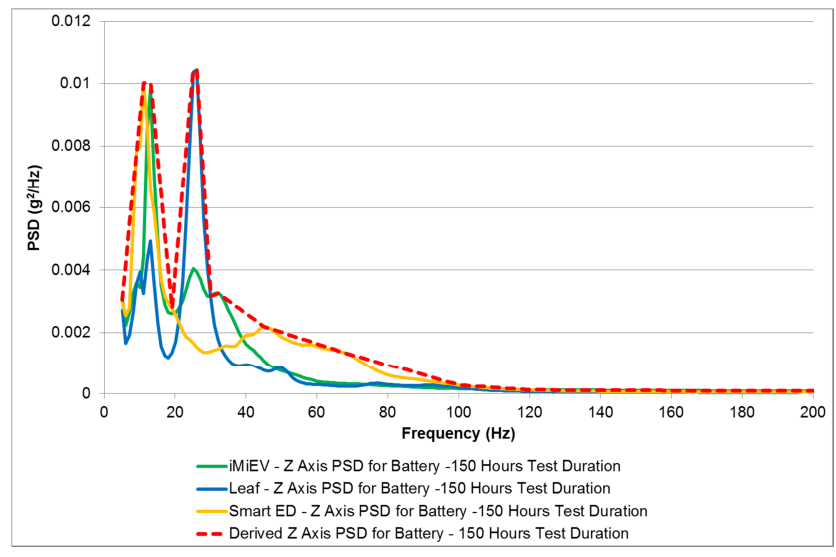

Figure 6: Example $\mathrm{Z}$ axis test profile derived by peak enveloping of derived PSD for each test vehicle

The derived profiles were defined by a maximum of 15 break points to ensure that they could be uploaded into a wide range of shaker system controllers. The subsequent synthesised vibration test profiles representative of 100,000 miles of durability for the $\mathrm{X}, \mathrm{Y}$ and $\mathrm{Z}$ axis of a RESS are illustrated in Figure 7.
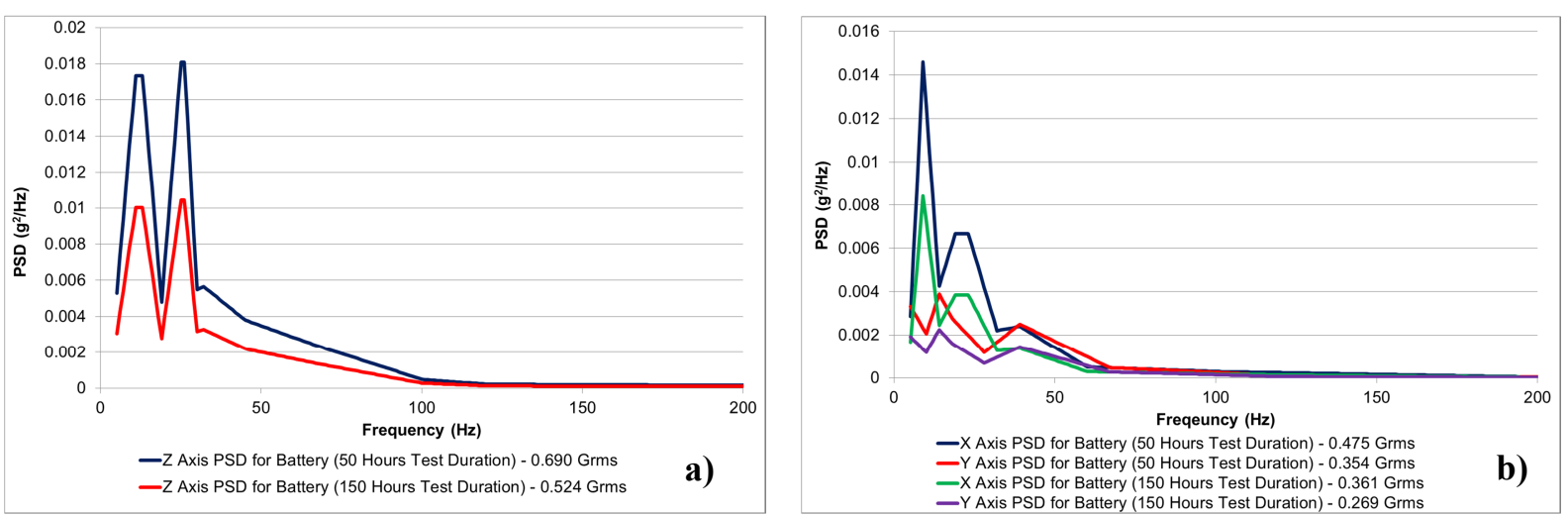

Figure 7: Synthesised Test PSD's for 50 and 150 Hours Test Duration per Axis a) Z axis PSD's b) X and Y axis PSD's

\section{Discussion - Comparison of synthesised test profile to current test standards}

Within this section the FDS and SRS of the synthesised profiles for the two different test durations of 150 and 50 hours per axis are compared to the current random profile tests available for the assessment of EV RESS assemblies and components as defined in section 2.2. The purpose of this is to understand the severity of test profiles derived from EV battery measurements and sequenced to 100,000 miles of UK $\mathrm{BEV}$ usage in comparison to contemporary standards.

\subsection{Comparison of FDS}

Figure 8 shows a comparison of the FDS of the derived EV profiles to current test standards. The fatigue loading of the derived 50 hour and 150 hour vibration profiles from this study are the same due to the same EV baseline data that they are generated from. 
Reviewing the potential fatigue damage for the $\mathrm{Z}$ axis (as shown in Figure 8a), it is noticeable the derived profiles have a comparable fatigue damage from 30 to $70 \mathrm{~Hz}$ as the SAE J2380 standard, however the synthesized profiles within this study typically have a greater fatigue loading from 5 to $18 \mathrm{~Hz}$. Both the ISO12405 and BS62660 Z axis profiles have a greater fatigue loading than the profiles generated from EV battery measurements, indicating they are too aggressive for durability assessments.
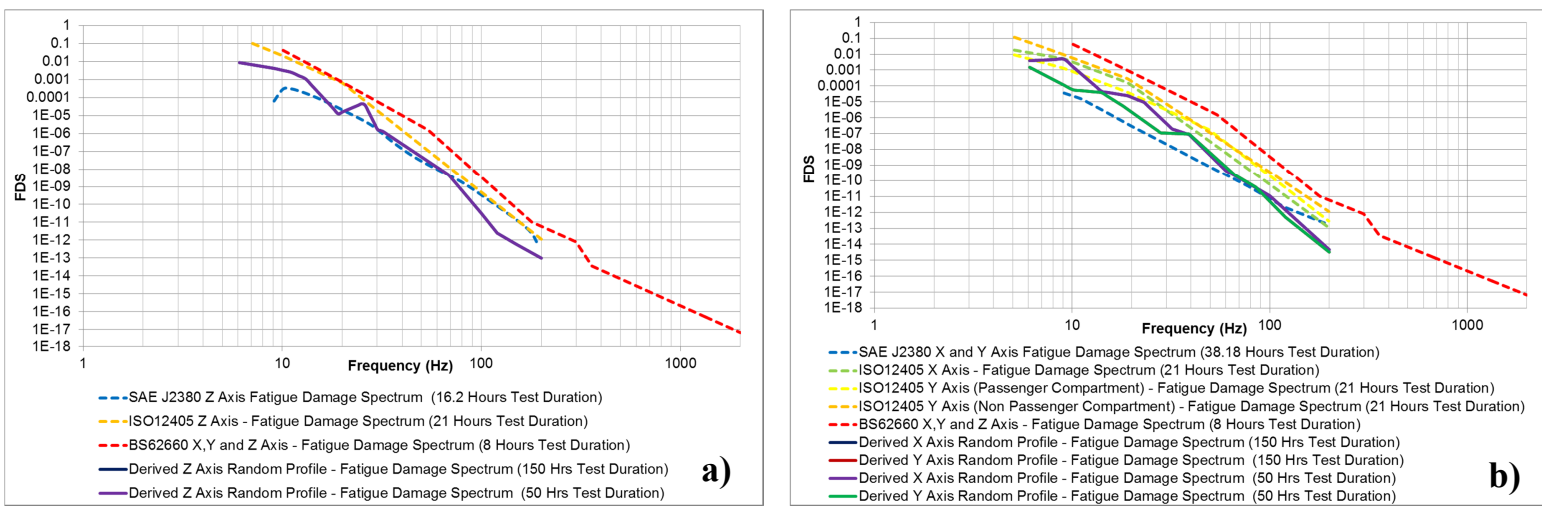

Figure 8: FDS of standards utilising random profiles vs FDS from derived test profiles a) $\mathrm{Z}$ axis, b) $\mathrm{X}$ and $\mathrm{Y}$ axis

Assessing the $\mathrm{X}$ and $\mathrm{Y}$ axis FDS (as shown in Figure 8b), it is noticeable that the potential fatigue damage of the SAE J2380 standard is lower than that generated by the synthesised test data from 10 to $60 \mathrm{~Hz}$. The SAE J2380 has been developed from North American market data, wherein the profiles developed in this study have been generated from European surfaces weighted to a UK customer usage. Also two "A segment vehicles" (Smart ED and Mitsubishi iMiEV) were measured within this study, both of which are likely to have greater roll and pitch moments due to their compact dimensions. Like the $\mathrm{Z}$ axis both BS62660 and ISO12405 show a significantly higher fatigue damage potential than profiles derived from 100,000 miles of durability suggesting that they are too aggressive to determine damage commutative with normal customer use and are only suitable for robustness studies.

\subsection{Comparison of SRS}

Figure 9 shows the SRS spectrum of the developed vibration profiles compared to that generated from ISO12405, SAE J2380 and BS62660 for the X, Y and Z axis.
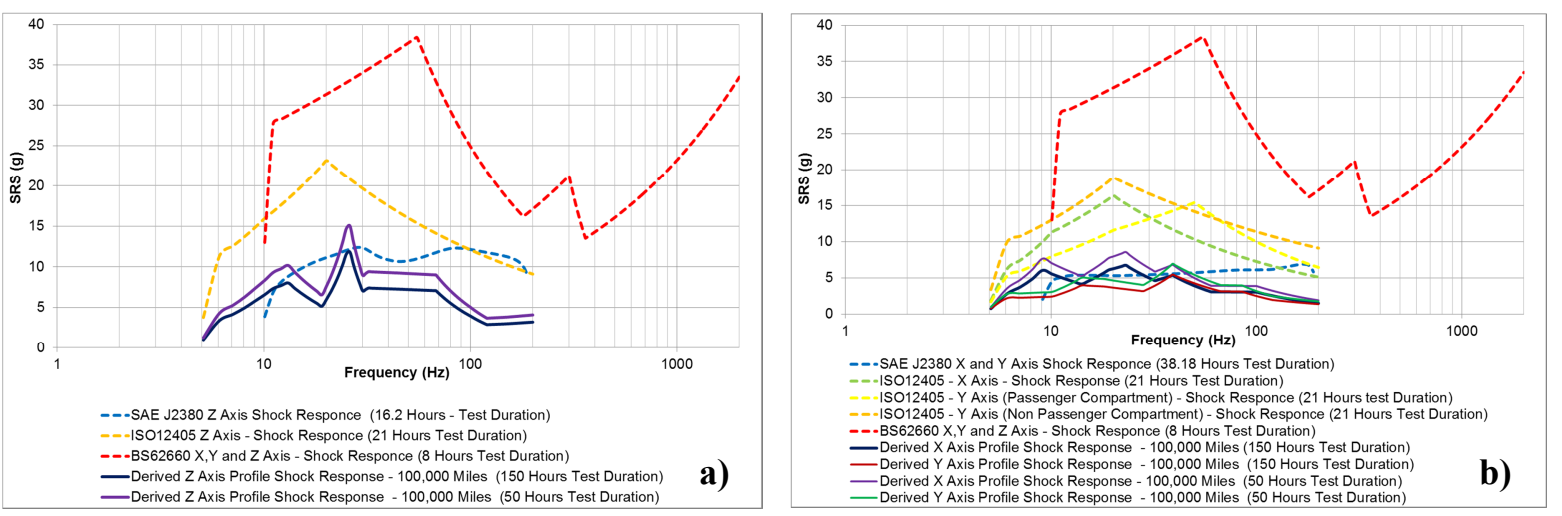

Figure 9: SRS of standards utilising random profiles vs SRS from derived test profiles a) $\mathrm{Z}$ axis, b) $\mathrm{X}$ and $\mathrm{Y}$ axis

BS62660 (which uses the same profile for all axis of the DUT) displays shock levels which are typically 2 to 4 times greater than that witnessed in profiles generated from EV battery data indicating that this test is unsuitable for durability assessment of RESS. Like BS62660, ISO12405 profiles apply a significantly higher shock load than that applied by durability profiles sequenced to replicate 100,000 miles of durability. A noteworthy observation is that SAE J2380 typically has a greater shock response than the derived profiles in the $Z$ (see Figure 9a) and $Y$ axis (see Figure 9b) however the shock loading in the $X$ axis (see Figure 9b) is often greater in the derived profiles than that applied by the standard. This likely to be a result of SAE J2380 applying a single profile for both X and Y axis of the test item. As a result difference in loading experienced by these different vehicle axis, are unaccounted for. 


\section{Discussion}

The comparison of current test standards to test profiles which have be sequenced to measured EV battery vibration data from multiple road surfaces has highlighted that the majority of random vibration tests within standards are overly compressed with respect to test duration. This has resulted in excessive shock loading. This may result in issues that would not be present in the real world operation and may hide fatigue issues that may not propagate due to the over accelerated nature of the test. The potential fatigue damage within BS62660 and ISO12405 is not representative of a vehicle life of 100,000 miles durability and highlights that these test profiles are suitable for a robustness test application and not a quantitative assessment of a RESS durability performance.

Whilst the SAE J2380 standard has been formulated to replicate 100,000 miles of durability, it could be improved by applying a more representative vibration profile for the $\mathrm{X}$ axis of the vehicle. Also it could apply vibration from $5 \mathrm{~Hz}$ upwards whilst still maintaining is suitability for a range of shaker facilities.

\section{Conclusions}

- This study has devised test profiles for testing the $\mathrm{X}, \mathrm{Y}$ and $\mathrm{Z}$ axis of a RESS and its sub components for two different test durations (50 hours and 150 hours per axis) that are representative of 100,000 miles of European durability surfaces sequenced to UK BEV road usage.

- The devised test profiles apply vibration from $5 \mathrm{~Hz}$ to $200 \mathrm{~Hz}$ ensuring that they can be replicated on a wide range of shaker systems whilst ensuring the DUT is excited within a suitable frequency range.

- The derived profiles in this study typically have a greater fatigue damage potential with a lower shock loading when compared to SAEJ2380.

- There is some correlation between the FDS of SAE J2380 and the derived test profiles in the study in the $\mathrm{Z}$ axis.

- BS62660 and ISO12405 both have significantly greater fatigue damage potential and greater shock loading when compared to vibration profiles developed from EV vibration measurements representative of 100,000 miles of durability. This indicates that they are unsuitable for durability testing as they replicate vibration loading that is unrepresentative of normal customer operation.

\section{Acknowledgments}

The authors would like to thank Dr Andrew Halfpenny, Robert Plaskitt and Mark Embra at HBM nCode for their support with this study. The authors would also like to thank Dr Stewart Birrell at the University of Warwick for the kind use of preliminary data from his study into road usage of BEV's. Finally the authors would like to thank all the team at Millbrook Proving Ground Ltd.

\section{References}

1. Parry-Jones, R., Driving success - a strategy for growth and sustainability in the UK automotive sector. 2013, Automotive Council UK: 1 Victoria Street, London, SW1H 0ET. p. 1-87.

2. Hooper, J. and J. Marco, Characterising the in-vehicle vibration inputs to the high voltage battery of an electric vehicle. Journal of power sources, 2014. 245: p. 510-519.

3. Hooper, J., et al., Vibration Durability Testing of Nickel Manganese Cobalt Oxide (NMC) Lithium-Ion 18650 Battery Cells. Energies, 2016. 9(52): p. 27.

4. Karbassian, A. and D.P. Bonathan, Accelerated Vibration Durability Testing of a Pickup Truck Rear Bed (2009-01-1406). SAE International, 2009(2009-01-1406): p. 1-5.

5. $\quad$ Risam, G.S., et al., Methodology for Accelerated Vibration Durability Test on Electrodynamic Shaker (2006-32-0081). SAE International, 2006. 1: p. 1-9.

6. Harrison, T., An Introduction to Vibration Testing. 2014, Naerum, Denmark: Bruel and Kjaer Sound and Vibration Measurement 11.

7. Hooper, J. and J. Marco, Experimental Modal Analysis of Lithium-ion Pouch Cells. Journal of Power Sources, 2015(285 (2015)): p. 247 to 259.

8. Moon, S.-I., I.-J. Cho, and D. Yoon, Fatigue life evaluation of mechanical components using vibration fatigue analysis technique. Journal of Mechanical Science and Technology, 2011. 25(3): p. 611-637.

9. Halfpenny, A. and D. Hayes, Fatigue Analysis of Seam Welded Structures using $n$ Code DesignLife. nCode. p. 1-21. 
10. Halfpenny, A., Methods for Accelerating Dynamic Durability Tests, in 9th International Conference on Recent Advances in Structural Dynamics. 2006: Southamption. p. 1-19.

11. Martin, D., A. Hiebl, and L. Krueger, Electromobility - challenges for structural durability. Materialwissenschaft und Werkstofftechnik, 2011. 42(10): p. 958-963.

12. Kjell, G. and J.F. Lang, Comparing different vibration tests proposed for li - ion batteries with vibration measurement in an electric vehicle, in EVS27. 2013, e of Sweden, Dept of Structural and Solid Mechanics: Barcelona, Spain. p. 1-11.

13. Harrison, T., Sine Vibration Theory. 2014, Naerum, Denmark: Bruel and Kjaer Sound and Vibration Measurement. 27.

14. Harrison, T., Random Vibration Theory. 2014, Naerum Denmark: Bruel and Kjaer Sound and Vibration Measurement.

15. Standards, B., BS ISO 12405-2:2012 -Electrically propelled road vehicles - Test specification for lithium-ion traction battery packs and systems Part 2: High-energy applications. 2012, British Standards. p. 1-60.

16. SAE, J2380: Vibration Testing of Electric Vehicle Batteries. 2013, SAE: Warrendale, USA. p. 1-7.

17. Standard, B., BS 62660-2:2011: Secondary lithium-ion cells for the propulsion of electric road vehicles. Reliability and abuse testing (British Standard). 2011, British Standard: London, UK.

18. Hooper, J., Study into the Vibration Inputs of Electric Vehicle Batteries, in School of Engineering. 2012, Cranfield University: Cranfield University. p. 1-116.

19. Engineers, S.o.A., SAE J670e Vehicle Dynamics Terminology 2008, SAE International: Warrendale, PA. p. 1-74.

20. Andrews, D., Millbrook Structural Durability Procedure. 2012, Millbrook Proving Ground: Millbrook, Bedfordshire, England.

21. Burgess, A., Transient Response of Mechanical Structures Using Modal Analysis Techniques, in Department of Mechanical Engineering. 1988, Imperial College London: London.

22. Meade, M. and C. Dillon, Signals and Systems. 2nd ed, ed. G. Bloodworth, A. Dorey, and J. Fidler. 1994, London, UK: Chapman and Hall. 167.

23. Rao, J. and K. Gupta, Introductory Course on Theory and Practice of Mechanical Vibrations. $2 \mathrm{nd}$ ed. 1999, Dehli, India: New Age International. 539.

24. Hooper, J., Vibration Durability Testing and Aging of Lithium Nickel Manganese Cobalt Oxide (NMC) Lithium Ion 18650 Cylindrical Cells, in Vehicle Electrification and Energy Storage. 2015, University of Warwick: Coventry, Warwickshire, UK. p. 244.

25. Halfpenny, A. and T. Walton, New Techniques for Vibration Qualification of Vibrating Equipment on Aircraft, in Aircraft Airworthiness \& Sustainment 2010. 2010, nCode: Austin, Texas, USA. p. 1-18.

\section{Authors}

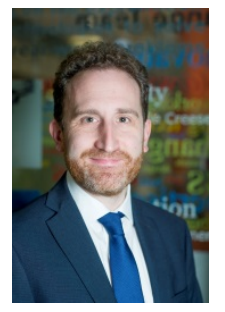

James Hooper obtained a BEng (Hons) in Automotive Engineering from the University of Hertfordshire in 2003 and an MSc in Automotive Technology Management from Cranfield University in 2013. He is currently undertaking an EngD (int.) at Warwick University, under the research title of "High Voltage Battery Durability and Noise Vibration and Harshness Evaluation" which has the innovation scope of "providing knowledge that allows manufacturers to improve the mechanical durability and performance of battery assemblies with respect to vibration".

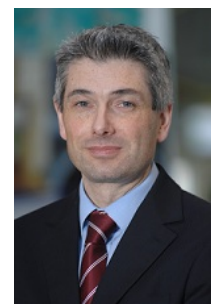

Dr James Marco is a Chartered Engineer and a member of the Institution of Engineering and Technology (IET). After graduating with an Engineering Doctorate, James worked for several years within the automotive industry on a number of different projects including those involving Ford (North America and Europe), Jaguar Cars, Land Rover and Daimler Chrysler. He is currently employed as a Reader in Vehicle Electrification and Energy Storage at WMG, University of Warwick. 